\title{
Primary Hyperaldosteronism Presenting as Hypokalemic Paralysis
}

\author{
Oza Harsh Nikhilkumar*, Dave Ruchir Bakulesh
}

\section{Oza Harsh Nikhilkumar*, Dave Ruchir Bakulesh}

Department of medicine, Sheth v.s. General Hospital, Ahmedabad, Gujarat, INDIA.

\section{Correspondence}

Dr. Oza Harsh Nikhilkumar

Resident doctor Department of medicine, Sheth v.s. General Hospital,

Ahmedabad, Gujarat-380054, INDIA.

Phone no: +91-9099348191

Email: harshjay@yahoo.in

\section{History}

- Submission Date: 26-05-2018;

- Revised Date: 12-09-2018;

- Accepted Date: 22-01-2019.

DOI : 10.5530/ijmedph.2019.1.8

Article Available online

http://www.ijmedph.org/v9/i1

\section{Copyright}

(C) 2019 Phcog.Net. This is an openaccess article distributed under the terms of the Creative Commons Attribution 4.0 International license.

\section{ABSTRACT}

Primary Hyperaldosteronism is excess production of aldosterone by the adrenal glands resulting in low renin levels. It is frequently associated with metabolic alkalosis and hypokalemia which may lead to intermittent attacks of paralysis. A young hypertensive male patient, on regular treatment with tablet losartan $50 \mathrm{mg}$ and tablet amlodipine $5 \mathrm{mg}$, once a day since last 4 years, presented with acute onset weakness of all four limbs. Serum potassium levels were found to be $1.6 \mathrm{mmol} / \mathrm{L}$, (normal range 3.5-5.1 mmol/L). He was treated with potassium supplements and after 3 days, his potassium levels were $3.6 \mathrm{mmol} / \mathrm{L}$, with improvement in his weakness. Tablet losartan was stopped and aldosterone to renin ratio with simultaneous potassium levels were ordered. The ratio was high (42.53) [reference range: 0.9-28.9] with simultaneous potassium levels of $3.5 \mathrm{mmol} / \mathrm{L}$. CECT abdomen also confirmed the presence of adrenal adenoma. One must be vigilant in evaluating for underlying causes in a patient presenting with hypokalemic hypertension. We report a case of conn's syndrome presenting with hypokalemic paralysis.

Key words: Hypokalemia, Primary hyperaldosteronism, Paralysis, Adrenal adenoma, Young hypertensive.

\section{INTRODUCTION}

Primary Hyperaldosteronism is a condition characterized by excess production of aldosterone by the adrenal glands resulting in low renin levels. ${ }^{1}$ It has a number of causes. About $66 \%$ of the cases are due to the enlargement of both adrenal glands and $33 \%$ of cases are due to an adrenal adenoma. ${ }^{2}$ Jerome W. Conn (1907-1994), the American endocrinologist was the first to describe adenoma as a cause of this condition in 1955 and hence it is also called as Conn's Syndrome. $^{2}$ The condition is often diagnosed in the third through fifth decade. Hypertension is usually mild to moderate but occasionally may be severe. ${ }^{3}$ Persistent aldosteronism is frequently associated with hypernatremia, polyuria and alkalosis, which predispose to attacks of tetany as well as to hypokalemic weakness and intermittent attacks of paralysis. ${ }^{4}$

\section{Case History}

A 40-year-old male hypertensive patient presented to our hospital with the chief complaint of weakness of all four limbs since 3 days. Weakness was acute in onset and progressive in nature. His blood pressure was $138 / 90 \mathrm{~mm}$ hg on arrival. On neurological examination, the power was grade one in all four limbs. The patient was a hypertensive since 4 years taking Tab. Losartan $50 \mathrm{mg}$ and Tab. Amlodipine $5 \mathrm{mg}$ once a day. On investigating, his serum potassium levels were $1.6 \mathrm{mmol} / \mathrm{L}$, (normal range 3.5-5.1 $\mathrm{mmol} / \mathrm{L}$ ). Arterial blood gas analysis showed metabolic alkalosis. Serum sodium levels were $144 \mathrm{meq} / \mathrm{L}$ (normal range: 135-145 meq/L) He was treated with intravenous $\mathrm{kcl}$ infusion with gradual improvement in serum potassium levels to normal range. Being a young hypertensive, renal Doppler was done to evaluate for renal artery stenosis, but turned out to be normal. On ultrasonography of the abdomen, he was found to be having prominent medullary pyramids with a $20 \times 17 \mathrm{~mm}$ sized hypoechoic lesion in the left suprarenal gland. Contrast Enhanced computerized Tomography (CECT) of the abdomen showed the presence of an adenoma in the left adrenal gland (Figure 1). His urine and serum osmolality were within the normal limits. Power in all four muscles improved to grade five with normalization of serum potassium level in a couple of days. To confirm the imaging findings of CECT abdomen with actual serum levels of aldosterone and renin, patient was advised to stop tablet losartan. He was also advised to drink coconut water. On follow up visit, we ordered plasma aldosterone to renin ratio and repeat serum potassium. Plasma Aldosterone level was found to be increased $(63.8 \mathrm{ng} / \mathrm{dL})$ [Lab reference range: $1.76-23.2 \mathrm{ng} / \mathrm{dL}$ ] and plasma renin activity was decreased $(1.5 \mathrm{ng} / \mathrm{ml} / \mathrm{hr})$ [Lab reference range: $2.9-10.8 \mathrm{ng} / \mathrm{ml} / \mathrm{hr}$ ]. Aldosterone to renin ratio was high 42.53 [Lab reference range: $0.9-28.9]$. serum potassium levels on follow up were $3.5 \mathrm{mmol} / \mathrm{L}$. Based on the above findings, diagnosis of primary hyperaldosteronism (Conn's Syndrome) was made. The patient was started on Tab. Spironolactone $25 \mathrm{mg}$ twice a day. Later on, patient underwent surgical resection of the adenoma.

Cite this article : Harsh N Oza and Ruchir B Dave. Primary Hyperaldosteronism Presenting as Hypokalemic Paralysis. Int J Med Public Health. 2019;9(1):31-3. 


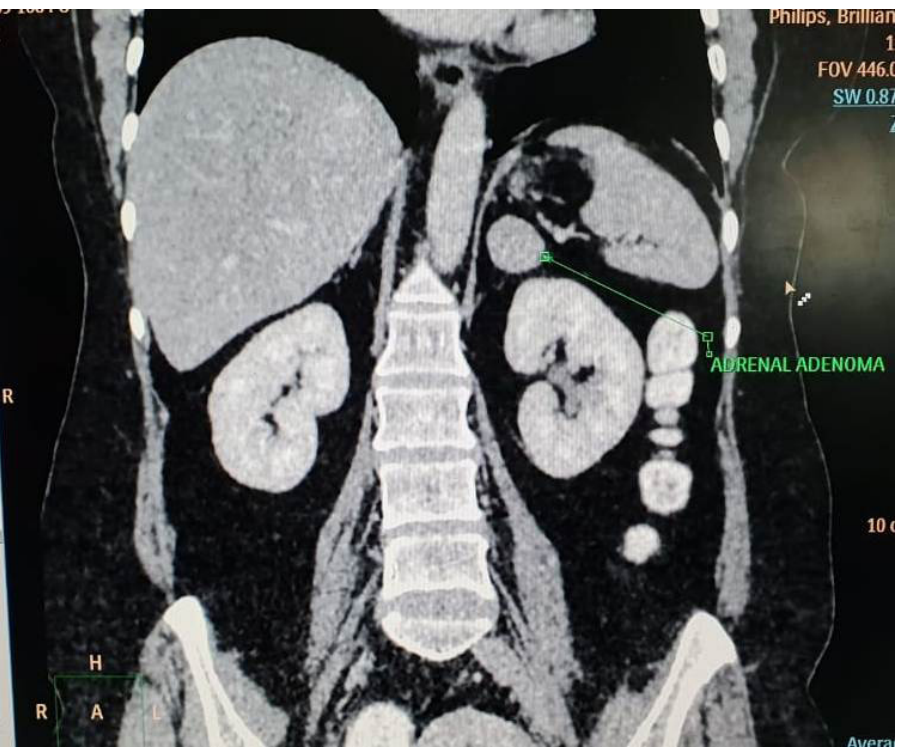

Figure 1: Left sided adrenal adenoma.

Source: department of radiology, sheth v.s. general hospital, Ahmedabad, Gujarat, India.

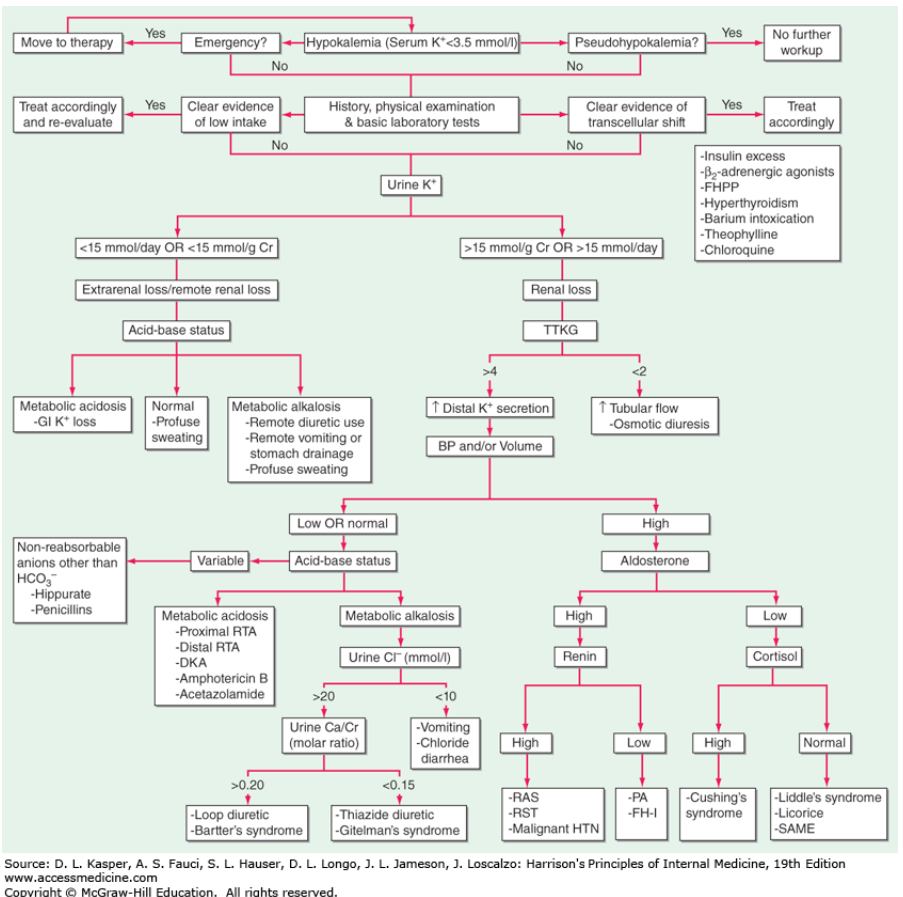

Figure 2: approach to a patient with hypokalemia.

\section{DISCUSSION}

Current statistics suggests that Primary Hyper-aldosteronism is the commonest cause of secondary hypertension. ${ }^{5}$ It is underdiagnosed because of the absence of hypokalemia. (only 9-37\% of PA cases present with hypokalemia), ${ }^{5}$ but its prevalence is estimated $4.3-9.5 \%$ in hypertensive patients and it commonly occurs between 30 and 50 years of age. ${ }^{6}$ There is an uncontrollable synthesis of aldosterone leading to increased sodium reabsorption, kaliuresis and renin suppression. All of these changes lead to end organ damage (heart, kidneys and brain) more severely than essential hypertension. ${ }^{7}$ Recent studies suggest that 10 to $15 \%$ of individuals with hypertension fulfill the biochemical criteria for primary aldosteronism. ${ }^{8}$ These studies have used the serum aldosterone to plasma renin activity ratio as a screening test to demonstrate this high prevalence. This frequency is much higher than that previously described when hypokalemia was used as a screening tool. ${ }^{9}$ Hypertension is a very common presenting feature in clinical practice. Our patient was a hypertensive since the past 4 years and presented with an acute onset muscle weakness due to hypokalemia. Approach for the patient of hypokalemia is shown in Figure 2. Finding of adrenal adenoma led to the suspicion of primary hyperaldosteronism, which was confirmed by further evaluation. In a hypertensive patient with unprovoked hypokalemia (i.e., unrelated to diuretics, vomiting or diarrhea), the prevalence of primary aldosteronism approaches $40-50 \% .{ }^{3}$ Common causes of primary aldosteronism includes Bilateral idiopathic (micro nodular) adrenal hyperplasia, Adrenal adenoma, Primary (unilateral) adrenal hyperplasia, Aldosterone-producing adrenocortical carcinoma, Familial Hyperaldosteronism, Ectopic aldosterone-producing adenoma or carcinoma. ${ }^{10}$

\section{CONCLUSION}

Young hypertensive patient, when presents with features suggestive of hypokalemia, underlying pathology related to adrenals must be kept in mind and appropriate investigations should be done to find out the etiology. This can help diagnose the cause of secondary hypertension and prevent false labeling of essential hypertension, which will ultimately lead to its better management.

\section{Drawbacks}

To confirm the diagnosis of adrenal adenoma, only alodosterone rennin ratio was used which was supported by ct scan findings. Due to unaffordability, no other confirmative investigation was possible.

\section{ACKNOWLEDGEMENT}

I would like to thank all three of my guide and mentor for their full support throughout the process.

1 DR. Monila N Patel (Professor and Head of Unit, General Medicine department, V.S. General Hospital, Ahmedabad, Gujarat, India)

1: Dr. Jyoti Vora (Associate Professor, General Medicine department, V.S. General Hospital, Ahmedabad, Gujarat, India)

3: Dr. Sneha Shah, (Assistant Professor, General Medicine department, V.S. General Hospital, Ahmedabad, Gujarat, India)

\section{CONFLICT OF INTEREST}

The authors declare no conflict of interest.

\section{ABBREVIATIONS}

CECT: Contrast Enhanced Computed Tomography.

\section{REFERENCES}

1. Stowasser M, Taylor PJ, Pimenta E, Ahmed AH, Gordon RD. Laboratory investigation of primary aldosteronism. The Clinical Biochemist Reviews. 2010;31(2):39-56. PMC 2874431 Freely accessible. PMID 20498828

2. Schirpenbach C, Reincke M. Primary aldosteronism: current knowledge and controversies in Conn's syndrome. Nature Clinical Practice Endocrinology and Metabolism. 2007;3(3):220-7. doi:10.1038/ncpendmet0430. PMID 17315030

3. Kotchen TA. Hypertensive Vascular Disease. Harrison's Principles of Internal Medicine, 19e New York, NY: McGraw-Hill. 2014

4. Chapter 50. The Myotonias, Periodic Paralyses, Cramps, Spasms and States of Persistent Muscle Fiber Activity. Adams and Victor's Principles of Neurology, 10e New York, NY: McGraw-Hill. 2014.

5. Funder JW, Carey RM, Fardella C, Gomez-Sanchez CE, Mantero F, Stowasser M, 
et al. Endocrine Society. J Clin Endocrinol Metab. 2008;93(9):3266-81.

6. Hannemann A, Wallaschofski H. Prevalence of primary aldosteronism in patient's cohorts and in population-based studies-a review of the current literature. Horm Metab Res. 2012;44(3):157-62.

7. Viola A, Tizzani D, Monticone S, Crudo V, Galmozzi M, Burrello J, et al. Diagnosis and treatment of unilateral forms of primary aldosteronism. Curr Hypertens Rev. 2013;9(2):156-65.
8. Calhoun D. Aldosteronism and hypertension. Clin J Am Soc Nephrol. 2006;1(5):1039-45.

9. Mosso L, Carvajal C, Gonzalez A, Barraza A, Avila F, Montero J, et al. Primary aldosteronism and hypertensive disease. Hypertension. 2003;42(2):161-5.

10. Henry M. Kronenberg Williams textbook of endocrinology ( $11^{\text {th }}$ ed.). Philadelphia: Saunders/Elsevier. 2008. ISBN 978-1-4160-2911-3.

Cite this article : Harsh N Oza and Ruchir B Dave. Primary Hyperaldosteronism Presenting as Hypokalemic Paralysis. Int J Med Public Health. 2019;9(1):31-3. 